\title{
Hypoxia inducible factor-1 mediates upregulation of urokinase-type plasminogen activator receptor gene transcription during hypoxia in cervical cancer cells
}

\author{
HIROTAKA NISHI $^{1}$, TORU SASAKI $^{1}$, YUZO NAGAMITSU ${ }^{1}$, FUMITOSHI TERAUCHI $^{1}$, \\ TAKESHI NAGAI ${ }^{2}$, TOSHITAKA NAGAO ${ }^{2}$ and KEIICHI ISAKA ${ }^{1}$ \\ ${ }^{1}$ Department of Obstetrics and Gynecology, and ${ }^{2}$ Department of Anatomic Pathology, \\ Tokyo Medical University, Shinjuku-ku, Tokyo 160-0023, Japan
}

Received September 18, 2015; Accepted October 26, 2015

DOI: $10.3892 /$ or.2015.4449

\begin{abstract}
Hypoxia occurs during development of cervical cancer and is considered to correlate with its invasion. Hypoxia mediates tumor cells to have more invasive property in a variety of cancers. Urokinase plasminogen activator receptor (UPAR) which mediates invasion is considered to be induced by hypoxia. We sought to determine the regulators of UPAR expression during hypoxia in cervical cancer. We showed that cervical cancer cell lines, CaSki and CA, were more invasive under hypoxic condition $\left(1 \% \mathrm{O}_{2}\right)$ than under normoxic condition $\left(20 \% \mathrm{O}_{2}\right)$ by invasion assays. Using western blot analysis, hypoxia enhanced the endogenous hypoxia-inducible factor (HIF)-1 $\alpha$ and uPAR protein expression. UPAR mRNA level was also upregulated by hypoxia using real-time RT-PCR. Overexpression of HIF-1 $\alpha$ which is induced by hypoxia activated the transcriptional activity of the UPAR promoter by luciferase assays. HIF-1 protein bound the putative HIF-1 response element on the UPAR promoter using electrophoretic mobility shift analysis, and additional luciferase assays show that this is essential for UPAR transactivation by HIF-1. HIF-1 overexpression enhanced the endogenous uPAR expression and introduction of siRNA for HIF- $1 \alpha$ diminishes uPAR expression during hypoxia. These results indicate the upregulation of UPAR by hypoxia in cervical cancer cells is mediated through HIF-1. In cervical cancer tissues, we also demonstrated that UPAR protein expression was detected in cervical cancer but not in normal cervix or cervical intraepithelial neoplasia (CIN) by immunohistopathological staining. Our results provide evidence that regulation of UPAR expression by HIF-1 represents a mechanism for cervical cancer invasion during hypoxia.
\end{abstract}

Correspondence to: Dr Hirotaka Nishi, Department of Obstetrics and Gynecology, Tokyo Medical University, 6-7-1 Nishishinjuku, Shinjuku-ku, Tokyo 160-0023, Japan

E-mail: nishih@tokyo-med.ac.jp

Key words: hypoxia, cervical cancer, uPAR promoter, invasion

\section{Introduction}

Hypoxia within solid tumors may have a profound impact in malignant progression. Hypoxia within the tumor mass is an independent marker of poor prognosis for patients with a variety of cancers including cervical cancers, soft tissue sarcoma and head neck cancers (1-3). Hypoxic stress underlies a number of biologically important processes in which cellular migration and invasion occur (4). Hypoxia may play an important role in promoting tumor metastasis and invasion into the extracellular matrix (5). Hypoxia upregulates the expression of the urokinase plasminogen activator receptor (uPAR) which is a component of a protease system implicated in tumor invasion and metastasis (6). The uPAR is activated by binding with its ligand, urokinase plasminogen activator (uPA), allowing the conversion of inactive plasminogen into plasmin that in turn can degrade extracellular matrix proteins, facilitating invasion by tumor cells (7).

Hypoxia-inducible factor (HIF)-1 is a heterodimeric transcriptional complex that plays a pivotal role in the regulation of cellular utilization of oxygen and is an essential regulator of angiogenesis in solid tumor and ischemic disorders. HIF-1 is composed of the bHLH-PAS proteins HIF-1 $\alpha$ and aryl hydrocarbon receptor nuclear translocator (ARNT). HIF-1 mediates the transcriptional response to oxygen deprivation by binding to HIF-1 response elements (HRE) within the promoters or enhancers of genes involved in glycolysis, glucose transport, erythropoiesis and angiogenesis $(8,9)$. The HIF-1 activity is critical for cancer development and HIF-1 is essential for proliferation, survival or differentiation of multiple tumor tissues (9). In light of the above considerations, we investigated how UPAR expression is induced by hypoxia in cervical cancer cell lines. We also sought to determine the regulator of uPAR expression during hypoxia. HIF-1 is a possible candidate for the regulator of uPAR expression.

\section{Materials and methods}

Samples. The samples were obtained from patients undergoing surgery or biopsy at Tokyo Medical University Hospital with informed consent. We used ten normal cervices and 35 cervical 
cancers. To extract total RNA, the tissues were finely minced into small pieces with scissors, washed in phosphate-buffered saline (PBS), snap-frozen and stored at $-80^{\circ} \mathrm{C}$. For immunohistochemistry analysis, the tissues were formalin-fixed and embedded in paraffin.

Cell culture. The human cervical cancer cell lines, CaSki and CA, were maintained in Modified Eagle Medium (MEM; Invitrogen, Carlsbad, CA, USA) supplemented with $10 \%$ fetal bovine serum (FBS). For hypoxic exposure, these cells $\left(1.0 \times 10^{7}\right.$ cells) were plated in $10 \mathrm{ml}$ of medium in $100-\mathrm{mm}$ dishes and incubated overnight in $1 \% \mathrm{O}_{2}$ in a water-jacketed $\mathrm{CO}_{2}$ incubator (NAPCO, Winchester, VA, USA) at $37^{\circ} \mathrm{C}$ in a humidified atmosphere with $5 \% \mathrm{CO}_{2}$ for indicated times. In experiments using transfected cells, each transfection was performed before exposure to hypoxia.

DNA plasmids. Sequence analysis of the human uPAR promoter revealed one putative binding site for HIF-1, the HRE motifs 5'-BACGTSSK-3'. The putative HIF binding site at position -34 to -39 was identified on the sense strand (10). Luciferase reporter constructs, puPAR-141-luc, containing the UPAR promoter which is produced by PCR were prepared by ligation into pGL3-basic vector (Fig. 3A). We prepared the puPAR-141mt-luc, where the putative HRE is mutated by replacement of ACG with TTT using PCR-based site-specific mutagenesis. HIF-1 $\alpha$ and ARNT constructs were kindly provided by Dr L. Eric Huang (Departments of Neurosurgery and Oncological Sciences, University of Utah, USA).

Invasion assays. For invasion assays, 12-mm-diameter Transwell polycarbonate filters (12-mm pore size; Costar) in a modified Boyden chamber were coated with Matrigel $(100 \mathrm{ml}$; Sigma, St. Louis, MO, USA) at 1:20 dilution in serum-free medium and air-dried for $24 \mathrm{~h}$. Cells $\left(5 \times 10^{4}\right)$ in the complete medium $(200 \mathrm{ml})$ were seeded into the inner chamber. A total of $600 \mathrm{ml}$ of the medium was added to the lower chamber, and the plate was incubated at $37^{\circ} \mathrm{C}$ in a $5 \% \mathrm{CO}_{2} / 95 \%$ air incubator $\left(20 \% \mathrm{O}_{2}\right)$. For hypoxic treatment, plates containing Boyden chambers were placed in $1 \% \mathrm{O}_{2}$ in a water-jacketed $\mathrm{CO}_{2}$ incubator (NAPCO) at $37^{\circ} \mathrm{C}$ in a humidified atmosphere with $5 \% \mathrm{CO}_{2}$ overnight. Cells on the lower surface of the filter were scraped with a rubber scraper into the medium from the lower chamber, pelleted, resuspended in the medium (50 $\mathrm{ml})$, and counted using a hemocytometer. Each condition was performed in quadruplicates, and the experiments were carried out twice.

Real-time RT-PCR analysis. Total RNA was isolated using Isogen reagent (Nippon Gene, Tokyo, Japan) and quantified by A260/A280 measurement using an Ultraspec 3000 (Amersham Biosciences, Piscataway, NJ, USA). Total RNA (50 mg) was reverse-transcribed into cDNA using an RT-PCR kit (Stratagene, La Jolla, CA, USA) according to the manufacture's recommendations.

Real-time PCR was performed for the quantitative estimation of the DNA level. PCR reactions $(20 \mathrm{ml})$ were set-up with the final concentrations of $5 \mathrm{mM} \mathrm{MgCl}_{2}, \mathrm{SYBR}-\mathrm{Green}$ Master Mix (2 ml; Roche Applied Science, Mannheim, Germany), cDNA (1:10 dilution; $5 \mathrm{ml}$ ), and forward and reverse primers
(0.3 mM each). The primer sequences were as follows: 5'-CAA CACCACCAAATGCAACG-3' (forward), and 5'-GGTTTTT CGGTTCGTGAGTG-3' (reverse). The reactions were then cycled in a LightCycler (Roche Applied Science) with the following parameters: denaturation for 1 cycle at $95^{\circ} \mathrm{C}$ for $10 \mathrm{sec}, 45$ cycles (temperature transition of $20^{\circ} \mathrm{C} / \mathrm{sec}$ ) of $95^{\circ} \mathrm{C}$ for $10 \mathrm{sec}, 62^{\circ} \mathrm{C}$ for $10 \mathrm{sec}$, and $72^{\circ} \mathrm{C}$ for $6 \mathrm{sec}$. Fluorescence readings were taken at $72^{\circ} \mathrm{C}$ and, melting curve analysis was performed with continuous fluorescence reading. The LightCycler software generated a standard curve (from measurements taken during the exponential phase of the amplification) that enabled the amount of each gene in each test sample to be determined.

Western blot analysis. CaSki and CA cells were seeded at $2.5 \times 10^{6}$ cells $/ 150 \mathrm{~mm}$ dish, and incubated overnight at $37^{\circ} \mathrm{C}$. Subsequently, cells were exposed to hypoxic conditions. Cells were harvested and lysed on ice for $30 \mathrm{~min}$. In lysis buffer [10 mM Tris (pH 8.0), $1 \mathrm{mM}$ EDTA, $400 \mathrm{mM}$ $\mathrm{NaCl}, 10 \%$ glycerol, $0.5 \% \mathrm{NP} 40,5 \mathrm{mM}$ sodium fluoride, $0.1 \mathrm{mM}$ phenylmetylsulphonyl fluoride and $1 \mathrm{mM}$ DTT], containing complete protease inhibitor cocktail (Boehringer Mannheim, Indianapolis, IN, USA). The lysate was centrifuged at $14,000 \mathrm{rpm}$ for $15 \mathrm{~min}$ and the soluble fractions were collected. Protein concentrations were measured using Bio-Rad protein assay kit (Bio-Rad Laboratories, Hercules, CA, USA). Equal amounts of protein $(40 \mathrm{mg})$ were loaded onto a 4-12\% SDS-polyacrylamide gel and subjected to electrophoresis at $200 \mathrm{~V}$ for $50 \mathrm{~min}$. The protein was transferred onto a polyviniylidene difluoride membrane and probed with an anti-uPAR antibody (FL-290; Santa Cruz Biotechnology, Santa Cruz, CA, USA), anti-HIF-1 $\alpha$ antibody (NB100-105; Novus Biologicals, Littleton, CO, USA), and anti-actin antibody (C4; Boehringer Mannheim). The same blot was probed with different antibodies after stripping the membrane. Each protein was detected by horseradish peroxidase-conjugated secondary antibody coupled with enhanced chemiluminescence western blotting detection reagents (Amersham Biosciences). Each band intensity was normalized to the intensity of the actin band.

Transfection and luciferase assays. Each cell line was seeded at $5.0 \times 10^{5}$ cells $/ 35-\mathrm{mm}$ dish and incubated overnight at $37^{\circ} \mathrm{C}$ in a $5 \% \mathrm{CO}_{2}$ incubator. For each transfection, empty or expression vectors $(1.0 \mathrm{mg})$ along with the promoter-luciferase DNA $(0.3 \mathrm{mg})$ were mixed in Opti-MEM $(0.2 \mathrm{ml})$ and a precipitate was formed using Lipofectamine 2000 (both from Invitrogen) according to the manufacturer's instructions. Cells were washed with Opti-MEM, and complexes were applied to the cells. After transfection for $24 \mathrm{~h}$, cells were harvested and extracts were prepared with the Glo Lysis Buffer (Promega, Madison, WI, USA). Luciferase activity was measured in extracts from triplicate samples using the Bright-Glo Luciferase Assay system (Promega).

Electrophoretic mobility shift assays. The HIF-1 protein was synthesized in vitro in the presence of unlabeled amino acids using the pcDNA3-HIF-1 $\alpha$ and pcDNA3-ARNT expression constructs with the coupled transcription/translation system (TNT) from Promega (11). Translated products were analyzed 
by western blotting using anti-HIF-1 $\alpha$ antibody (NB100-105; Novus Biologicals).

Oligonucleotides containing the HIF-1 consensus DNA-binding site from uPAR promoter (HRE/uPAR) and the HIF-1 binding site from the erythropoietin promoter (HRE) were purchased as single-stranded DNAs from Genosys Biotechnologies (Woodlands, TX, USA). Doublestranded oligonucleotides were prepared by annealing complementary oligonucleotides, in a buffer containing $10 \mathrm{mM}$ Tris (pH 8.0), $500 \mathrm{mM} \mathrm{NaCl}$ and $1 \mathrm{mM}$ EDTA. The sequences of the complementary pairs were as follows: 5'-AAGGAGAGAAGACGTGCAGGGACCCC-3' and 5'-GGGGTCCCTGCACGTCTTCTCTCCTT-3' (HRE/uPAR); 5'-TCTGTACGTGACCACACTCACCTC-3' and 5'-GAGGTGAGTGTGGTCACGTACAGA-3' (HRE). Equimolar amounts of the complementary oligonucleotides were mixed in a $1.5-\mathrm{ml}$ microcentrifuge tube and placed in a heat block at $95^{\circ} \mathrm{C}$. The heat block was allowed to cool to room temperature, and the samples were desalted on a G-25 Microspin column (Amersham). The double-stranded oligonucleotides were end-labeled with ${ }^{32} \mathrm{P}$ using $\mathrm{T} 4$ polynucleitide kinase and $\left[\gamma^{32} \mathrm{P}\right]-\mathrm{ATP}$. For electrophoretic mobility shift analysis, end-labeled double stranded oligonucleotides, $5,000 \mathrm{cpm}$, were incubated with HIF-1 protein $(2 \mathrm{ml})$ prepared by in vitro transcription/translation at room temperature $\left(22^{\circ} \mathrm{C}\right)$ for $30 \mathrm{~min}$ in the presence of a binding buffer containing $10 \%$ glycerol, $20 \mathrm{mM}$ HEPES (pH 7.5), $25 \mathrm{mM} \mathrm{KCl,} 2 \mathrm{mM}$ DTT, $2 \mathrm{mM} \mathrm{MgCl}{ }_{2}, 0.4 \% \mathrm{NP}-40$ and $1 \mathrm{mg}$ sheared salmon sperm DNA. When competition assays were performed, an unlabeled HIF-1 consensus sequence oligonucleotide was incubated with proteins and buffer for $5 \mathrm{~min}$ before the addition of each labeled oligonucleotide. For supershift assays, $0.5 \mathrm{mg}$ of HIF-1 $\alpha$ antibody (OZ15; Lab Vision Corporation, Fremont, CA, USA) was incubated with the binding mixtures for $5 \mathrm{~min}$ before the addition of the labeled oligonucleotide. Samples $(20 \mathrm{ml})$ were loaded onto a $5 \%$ non-denaturing polyacrylamide gel and subjected to electrophoresis at $150 \mathrm{~V}$ for $1 \mathrm{~h}$ using 0.5X Tris-borate EDTA [1X Tris-borate EDTA: $89 \mathrm{mM}$ Tris, $8 \mathrm{mM}$ boric asid and $2 \mathrm{mM}$ EDTA (pH 8.3)] as running buffer. After electrophoresis, gels were transferred to Whatman 3 MM paper and exposed to Kodak XAR film with intensifying screens at $-80^{\circ} \mathrm{C}$.

siRNA transfection. Gene silencing was achieved by transient transfection of siRNA oligonucleotides encoding specific sequences for HIF-1 $\alpha$ according to the manufacturer's instructions (Santa Cruz Biotechnology). In brief, CaSki and CA were plated overnight in antibiotic-free medium to reach $50 \%$ confluency. Cells were transfected the following morning using Lipofectamine 2000 with $100 \mathrm{pmol} / \mathrm{ml}$ of siRNA oligonucleotides. Control siRNA was transfected to exclude non-specific effects. After exposure to $1 \% \mathrm{O}_{2}$ for $24 \mathrm{~h}$, cells were harvested for protein.

Immunohistopathological analysis. Immunohistochemistry was performed on representative formalin-fixed, paraffin embedded sections. Each tissue block was sectioned at 4-mm thickness, deparaffinized in xylene and rehydrated in graded alcohols. Primary antibodies against uPAR (CD87, clone HD-uPAR-13.1; 1:50 dilution; American Diagnostica,
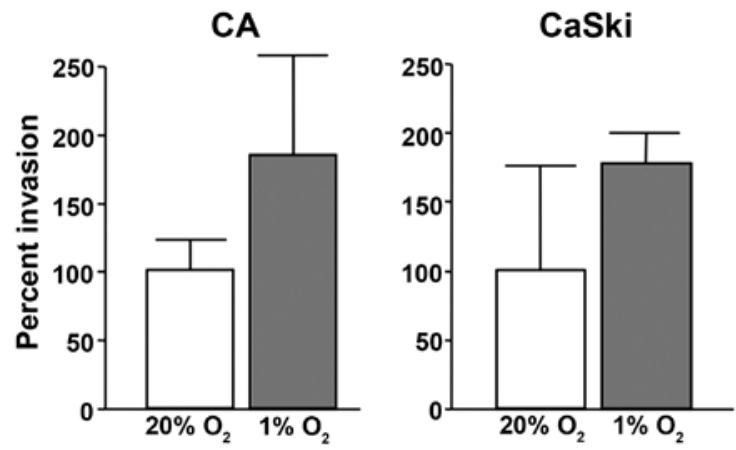

Figure 1. Hypoxia induces invasion in cervical cancer cells. Error bars indicate standard deviation from quadruplicate assays.

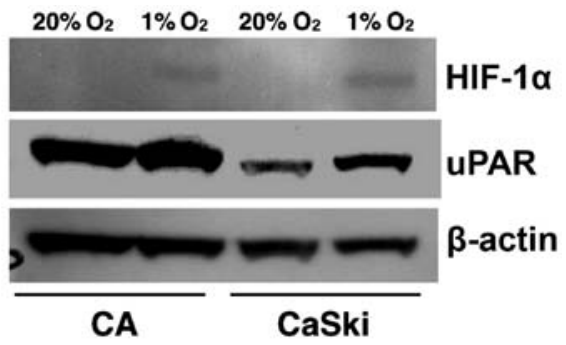

Figure 2. Hypoxia induces uPAR protein expression. CaSki and CA cells were cultured at $20 \% \mathrm{O}_{2}$ or $1 \% \mathrm{O}_{2}$ for $24 \mathrm{~h}$. Whole cell extracts $(40 \mathrm{mg})$ were prepared and subjected to western blot analysis.

Stamford, CT, USA) and HIF-1 $\alpha$ (NB100-105, clone H1alpha67; 1:500 dilution; Novus Biologicals) were used. Pretreatment for unmasking of antigens was carried out either via protease XXIV (Sigma Chemicals, Perth, WA, USA) for $10 \mathrm{~min}$ at room temperature for UPAR, or by autoclaving for $10 \mathrm{~min}$ at $110^{\circ} \mathrm{C}$ for $\mathrm{HIF}-1 \alpha$.

\section{Results}

Hypoxia mediates invasion. To determine the functional correlates of hypoxia-induced UPAR expression and invasion, we first compared the invasion of cervical cancer cells through a reconstituted basement membrane (Matrigel). The cervical cancer cell line, CaSki and CA, were incubated in hypoxic $(1 \%$ $\left.\mathrm{O}_{2}\right)$ and normoxic conditions $\left(20 \% \mathrm{O}_{2}\right)$, respectively. Invasion assays showed that these cells were 2-fold more invasive under hypoxic conditions than under normoxic conditions (Fig. 1).

Hypoxia induces endogenous $u P A R$ expression. To analyze whether there is a correlation between HIF- $1 \alpha$ and UPAR, we examined the effect of hypoxia on HIF-1 $\alpha$ and UPAR expression in cervical cancer cell line, CaSki and CA. Whole cell extracts prepared from controls and from cells exposed to $1 \% \mathrm{O}_{2}$ for $24 \mathrm{~h}$ were subjected to western blot analysis. As shown in Fig. 2, both HIF-1 $\alpha$ and uPAR protein expressions were increased significantly under hypoxic conditions. These results indicate that hypoxia induces the endogenous expressions of UPAR.

HIF-1 transactivates the $u P A R$ promoter. To examine whether the induction of UPAR expression by hypoxia is mediated 
A
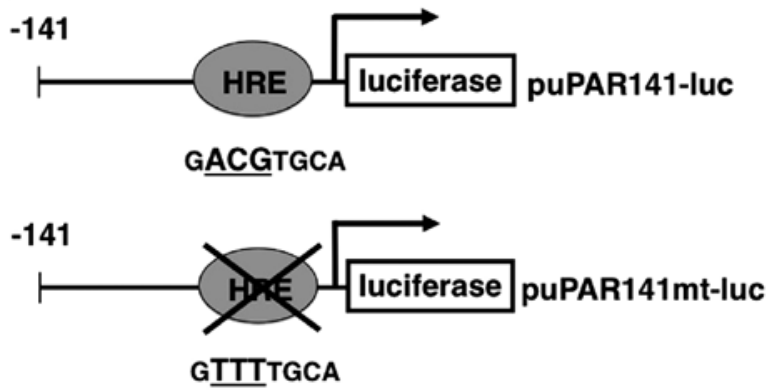

B
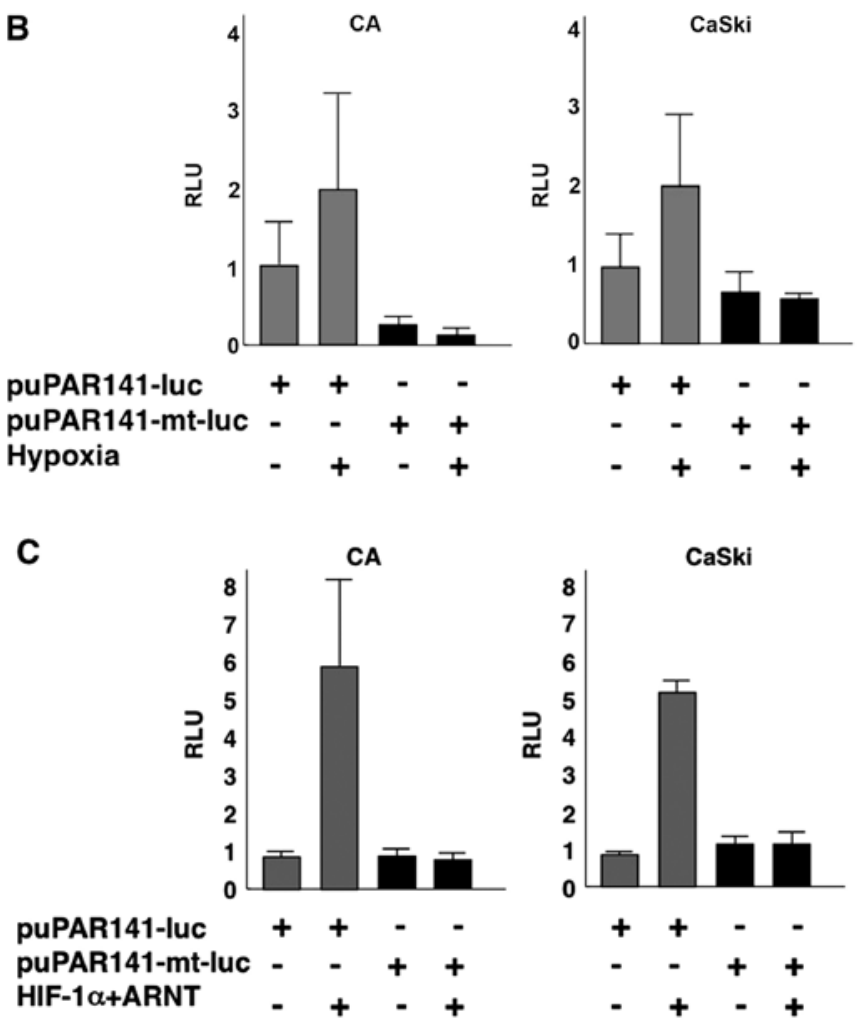

Figure 3. Transactivation of uPAR promoter activity by hypoxia exposure and HIF-1 overexpression. (A) The schematics of the HIF-1 response elements and the puPAR141-luc and puPAR141mt-luc reporters are shown. (B) CaSki and CA cells were transfected with the puPAR141-luc/puPAR141mt-luc $(0.3 \mathrm{mg})$ in hypoxic conditions $\left(1 \% \mathrm{O}_{2}\right)$ and activity reported as relative luminescence units (RLU). Error bars indicate standard deviation in triplicate assays. (C) CaSki and CA cells were co-transfected with the puPAR141luc/puPAR141mt-luc $(0.3 \mathrm{mg})$ and $1.0 \mathrm{mg}$ of HIF-1 expression constructs (HIF-1 $\alpha$ and ARNT) or empty vector, pcDNA3 in hypoxic conditions (1\% $\mathrm{O}_{2}$ ) and activity reported as relative luminescence units (RLU). Error bars indicate standard deviation in triplicate assays.

via a transcriptional mechanism, CaSki and CA cells were transfected with puPAR-141-luc (Fig. 3A) and then exposed to $1 \% \mathrm{O}_{2}$ for $24 \mathrm{~h}$. Hypoxia transactivated the uPAR promoter by 2-fold (Fig. 3B). Additional cotransfection experiments were performed with puPAR-141-luc, HIF-1 $\alpha$ and ARNT or empty vectors. HIF-1 overexpression transactivated the uPAR promoter by 5-6 fold (Fig. 3C).

The UPAR promoter contains a putative HRE. To confirm whether the UPAR promoter regions are responsible for transactivation by HIF-1, we prepared a reporter construct, puPAR-141mt-luc, where the putative HRE is mutated by replacement of AGG with TTT (Fig. 3A). Neither hypoxia nor
HIF-1 overexpression increased the activity of this mutated promoter, indicating that this putative HRE (HRE/uPAR) is essential for the regulation of $\mathrm{UPAR}$ by hypoxia and HIF-1 (Fig. 3B and C).

HIF-1 interacts with the putative HRE in the UPAR promoter. To determine whether HIF-1 has direct interaction with the HRE on the UPAR promoter, electrophoretic mobility shift assays were performed. Oligonucleotide corresponding to nucleotides -50 to -25 (HRE/uPAR) of the UPAR promoter was incubated with HIF-1 $\alpha$ and ARNT prepared by in vitro transcription/translation and subjected to electrophoresis. A DNA-protein complex was formed when HRE/UPAR was incubated with the HIF-1programmed rabbit reticulocyte lysate (Fig. 4A), but not with the unprogrammed lysate (data not shown). This complex was specifically retarded by anti-HIF-1 $\alpha$ antibody (Fig. 4). The addition of a 30-fold molar excess of cold HIF-1 consensus oligonucleotide (HRE) markedly reduced binding (Fig. 4A). To additionally substantiate a HIF-1 binding to this oligonucleotide, we performed competition assays using end-labeled HIF-1 consensus oligonucleotide and cold HRE/uPAR as a competitor. The unlabeled HRE/uPAR competed with HIF-1 binding to the wild-type probe when present in the reaction at 50- and 200-fold molar excess (Fig. 4B). These results confirm that HIF-1 binds to the HRE/uPAR and indicate that the affinity of HIF-1 binding to the HRE/uPAR is similar to that of the consensus HIF-1 sequence.

These data indicate that hypoxia-induced uPAR expression is induced by the enhanced activity of HIF-1 on the HRE/uPAR promoter. Taken together, the putative HIF-1 binding site in the proximal region of the UPAR promoter is essential for the regulation of uPAR.

Disruption of the UPAR expression by HIF-1 siRNA. HIF-1 $\alpha$ siRNA was previously used to inhibit HIF-1 $\alpha$ expression (12). In the present study, we used this HIF-1 $\alpha$ siRNA to examine whether hypoxia-induced UPAR expression is mediated by HIF-1 upregulation. When CaSki cells were transfected with siRNA and exposed to hypoxic conditions, the HIF-1 $\alpha$ and UPAR expressions were downregulated compared with the control siRNA transfected cells (Fig. 5A). The level of actin was monitored as a control and was found to be unaltered by siRNA (Fig. 5A). Similar results were obtained using CA cells (Fig. 5A). These results indicate that HIF-1 $\alpha$ is required for hypoxia induced UPAR expression.

To examine the effect on invasiveness by HIF-1 $\alpha$ knockdown, we performed invasion assay in CaSki and CA cells after HIF-1 $\alpha$ siRNA tranfection. Downregulation of HIF-1 expression significantly diminishes invasion in cervical cancer cells (Fig. 5).

uPAR $m R N A$ expression in cervical cancer tissue. The expression of UPAR mRNA was examined in cervical cancer from 35 patients and normal cervix from 10 patients who suffered from uterine myoma or prolapse of the uterus. Triplicate measurements were carried out. uPAR mRNA levels were much higher in cervical cancer than in normal tissues (Fig. 6).

Localization of the $U P A R$ expression. Immunohistochemical analysis of UPAR may lead to the understanding of neoplastic 

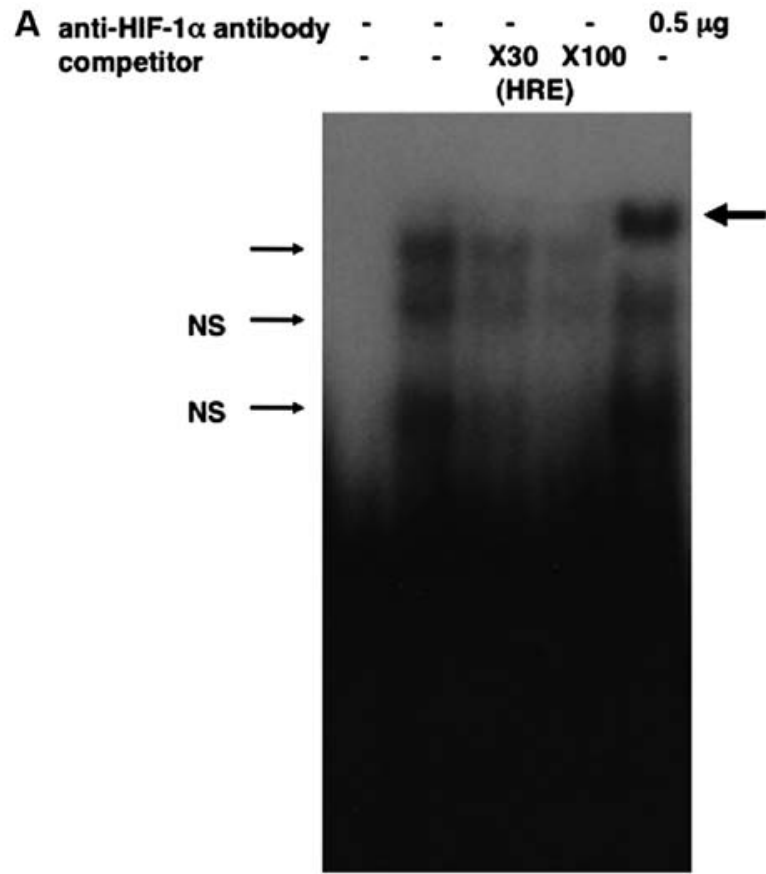

Probes:

HRE/UPAR

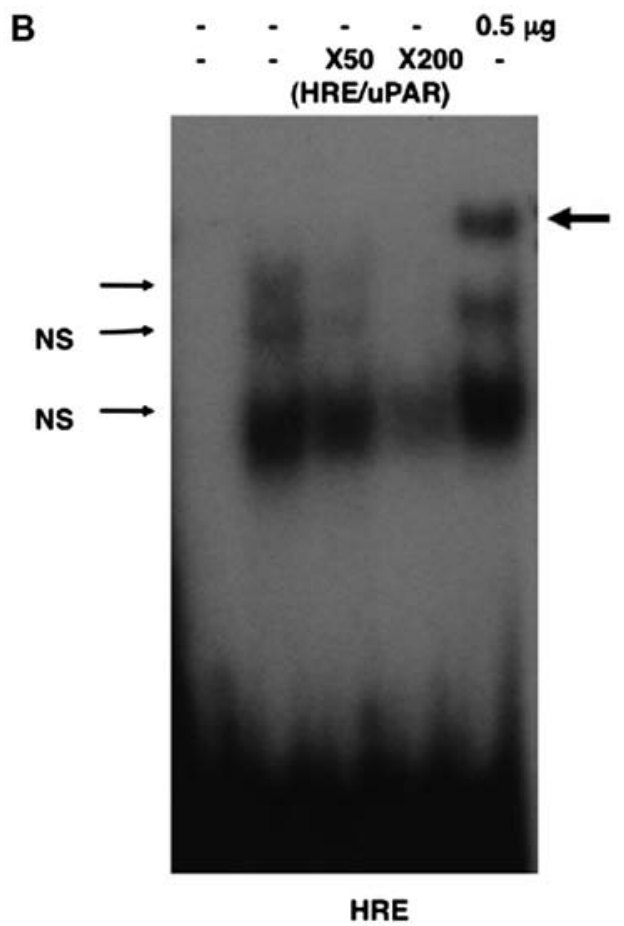

Figure 4. Analysis of HIF-1 interaction with the putative HRE in the uPAR promoter. (A) ${ }^{32} \mathrm{P}$ end-labeled HRE/uPAR oligonucleotide was used as a probe. For the competition assays, 30- or 100-fold molar excess of the HRE was used. For the supershift assay, anti-HIF- $1 \alpha$ antibody ( $0.5 \mathrm{mg})$ was added into the binding reaction. The thin arrow indicates HIF-1/DNA complexes and the thick arrow indicates supershifted bands. (B) The HIF-1 consensus oligonucleotide was end-labeled with ${ }^{32} \mathrm{P}$. For the competition assays, 50- or 200-fold molar excess of HRE/uPAR was added to the binding reaction, respectively. For the supershift assay, anti-HIF-1 $\alpha$ antibody $(0.5 \mathrm{mg})$ was added into binding reaction. The thin arrow indicates HIF-1/DNA complexes and the thick arrow indicates supershifted bands. NS, non-specific.

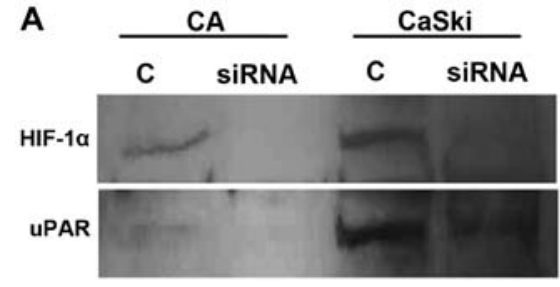

B
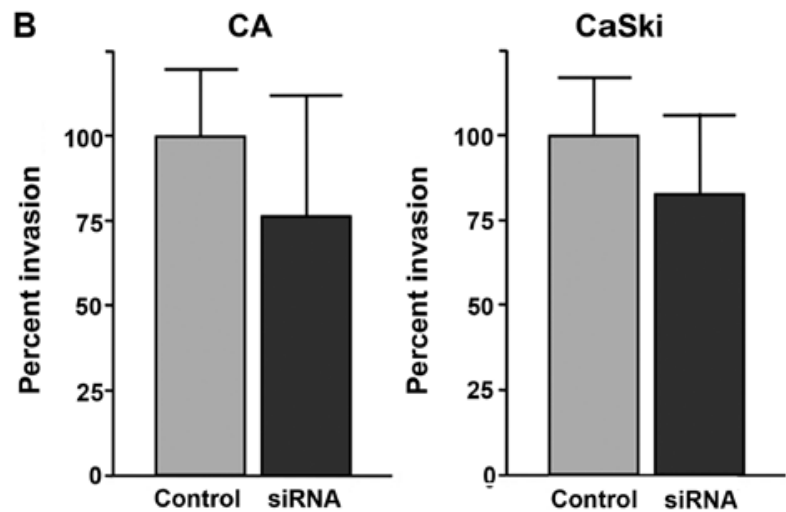

Figure 5. (A) Disruption of uPAR expression by the HIF-1 $\alpha$ siRNA. CaSki and CA cells were transfected with the HIF-1 $\alpha$ siRNA or control siRNA using Lipofectamine 2000. Cells were then exposed to hypoxic conditions $\left(1 \% \mathrm{O}_{2}\right)$. A cell lysate was prepared after $24 \mathrm{~h}$ and analyzed by western blotting for protein level using antibodies to HIF-1 $\alpha$, uPAR and actin. (B) HIF-1 $\alpha$ siRNA diminishes invasion in cervical cancer cells.

progression of invasion in cervical carcinogenesis. Increased nuclear staining of HIF-1 $\alpha$ was observed in invasive cervical

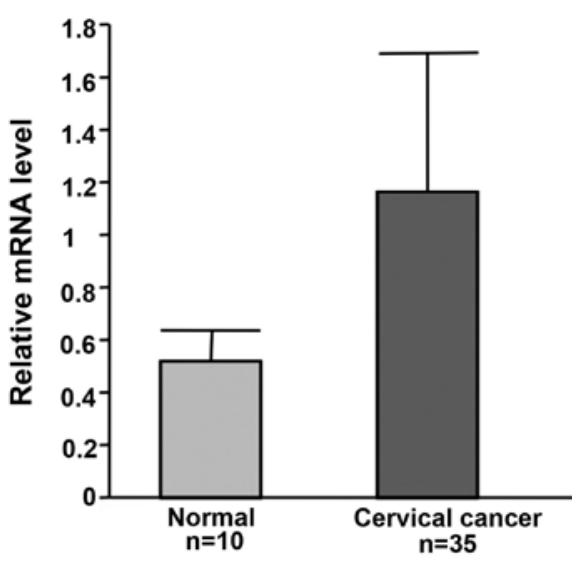

Figure 6. uPAR mRNA level in cervical cancer.

cancer tissue samples (Fig. 7C). However, no or faint staining was observed in CIN3 (Fig. 7A). High-level cytoplasmic staining of uPAR was detected in invasive cervical cancer, whereas not in CIN3 (Fig. 7B and D).

\section{Discussion}

Tumor cells need to migrate through the extracellular matrix and invade blood vessels into systemic circulation to be disseminated to metastatic organs $(13,14)$. Firstly, tumor cells detach from the primary tumor, invade blood vessels and then metastasize in organs where they form the secondary lesion. In spite of significant progress in cancer biology, it is not known 


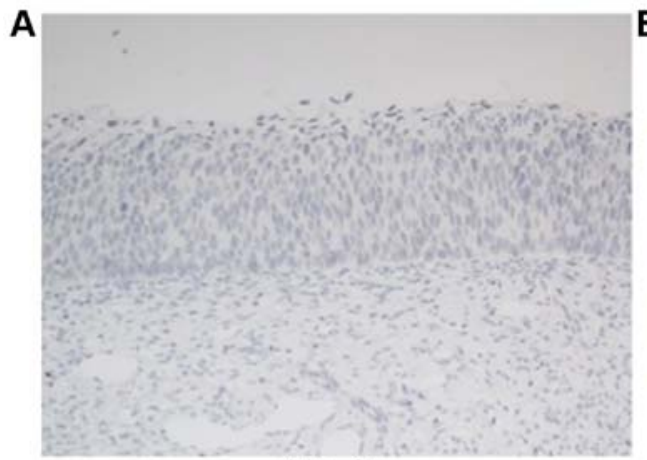

HIF-1a

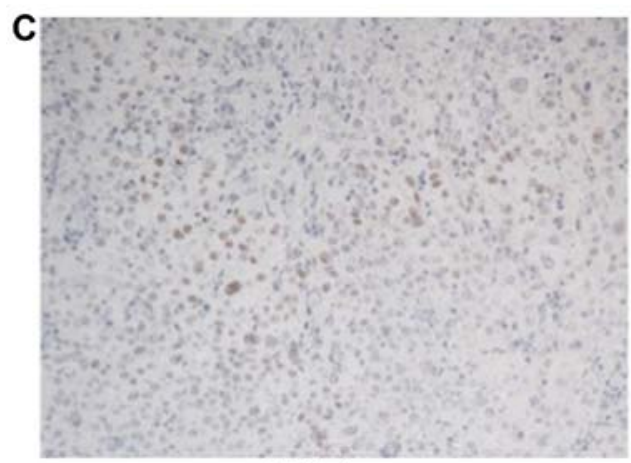

HIF-1 $\alpha$

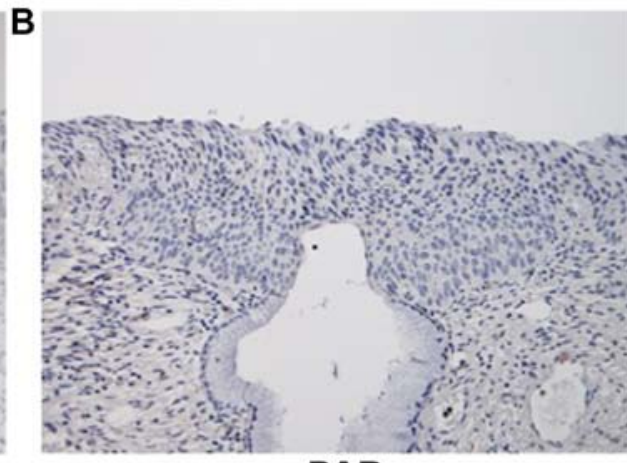

UPAR

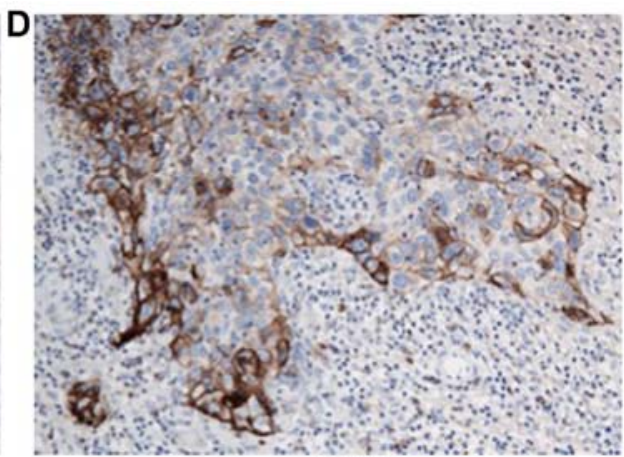

UPAR

Figure 7. Immunohistochemical staining of HIF-1 $\alpha$ and uPAR in cervical cancer. (A) CIN3 shows no staining with HIF-1 $\alpha$ antibody. (B) CIN3 shows no staining with uPAR antibody. (C) Increased nuclear staining was observed in invasive cervical cancer. (D) Strong cytoplasmic staining was detected in invasive cervical cancer. (A-D) Magnification, x100.

why only some but not all cells of a clonal tumor population acquire the ability to migrate through the tissue barriers (14). One hypothesis is that specific transient regional tumor microenvironment of low oxygen mediates a distinctive epigenetic gene expression profile in a subset of cells, which likely causes selection of more invasive cell clones $(15,16)$. Tumor hypoxia is one of the most critical situations during development of tumor invasion.

Our data show that HIF-1 transactivates the uPAR promoter and then mediates the induction of UPAR and invasion in cervical cancer cells during hypoxia. We have also shown that the protein level of UPAR in cervical cancer samples is higher than that in normal cervix. The level of uPAR was increased under hypoxic conditions, as determined by real-time RT-PCR analysis and western blotting in cervical cancer cell lines. When siRNA was used to reduce HIF-1 $\alpha$ expression, not only uPAR expression but also invasiveness was significantly diminished during hypoxia. According to electrophoretic mobility shift assay, we identified the active HRE in the uPAR core promoter. These findings may be relevant to several biological processes in which cell invasion occurs. For example, increased expression of uPAR in cancer may facilitate their invasion through hypoxic regions of the stroma (17). In addition, increased expression of UPAR is enhanced in migrating endothelial cells in vitro, and the fact that neovascularization of transplanted tumors in vivo is inhibited by $\mathrm{UPAR}$ antagonists suggests a role for hypoxia-stimulated UPAR expression in tumor angiogenesis (18-20). uPAR antagonists inhibit tumor metastasis, as well as local invasion, perhaps explaining the association of elevated UPAR levels in cervical, breast and other types of carcinomas with a poor clinical outcome (21-23).

Correlation between HIF-1 and regulation of UPAR has rarely been shown. The protease system of uPA/uPAR and metalloproteinases participate in the metastatic disease progression, which depends on hypoxia (13). A previous study showed that exposure of MDA-MB231 human breast carcinoma cells to hypoxia upregulated uPAR expression and increased invasion (17). It has also shown that these effects were prevented by incubating the cells with a blocking antibody to uPAR (17). It was hypothesized in that previous study that HIF-1 may be involved in the transcriptional activation of the UPAR gene (17). Also, Büchler et al has shown that the effects of hypoxia on UPAR and invasion were mediated directly by HIF-1 in pancreatic cancer cells (24).

The HRE (5'-RCGTG-3') overlaps the E-box (CACGTG), which is known to bind to several nuclear factors, such as c-Myc, Max and Mad (25-28). It is unclear whether HIF-1 competes with these factors for binding to these sites, whereas recent findings showed that hypoxia downregulated the c-Myc expression (29). Under hypoxic conditions, HIF-1 $\alpha$ may play a predominant role in regulating promoter activity of UPAR. Taken together, these data strongly indicate that hypoxia-induced UPAR expression is due to the enhanced activity of HIF-1 on the UPAR promoter. Furthermore, the proximal HRE in the UPAR promoter is essential for the upregulation of uPAR during hypoxia since the UPAR promoter was no longer transactivated by hypoxia when we 
used the puPAR-141mt-luc which had the mutated putative HRE by replacement of AGG with TTT.

These data may be important for future therapeutics since local tumor invasion and early metastatic progression are the most challenging clinical features of cervical cancer. The coordinated activation by HIF-1 of a large battery of target genes, the protein products of which perform diverse but related functions contributing to tumor invasion, suggests that inhibitors of HIF-1 activity may have therapeutic utility as anticancer agents (30). In conclusion, our results indicate that hypoxia-induced upregulation of UPAR is mediated by HIF-1 in cervical cancer cells, and provide evidence that regulation of UPAR expression by HIF-1 represents a mechanism for invasive cervical cancer during hypoxia.

\section{Acknowledgements}

The present study was supported by Grants-in-Aids from the Ministry of Education, Culture, Sports, Science and Technology of Japan (MEXT).

\section{References}

1. Brizel DM, Scully SP, Harrelson JM, Layfield LJ, Bean JM, Prosnitz LR and Dewhirst MW: Tumor oxygenation predicts for the likelihood of distant metastases in human soft tissue sarcoma. Cancer Res 56: 941-943, 1996.

2. Brizel DM, Sibley GS, Prosnitz LR, Scher RL and Dewhirst MW: Tumor hypoxia adversely affects the prognosis of carcinoma of the head and neck. Int J Radiat Oncol Biol Phys 38: 285-289, 1997.

3. Vaupel P, Thews O, Mayer A, Höckel S and Höckel M: Oxygenation status of gynecologic tumors: What is the optimal hemoglobin level? Strahlenther Onkol 178: 727-731, 2002.

4. Duong HS, Le AD, Zhang Q and Messadi DV: A novel 3-dimensional culture system as an in vitro model for studying oral cancer cell invasion. Int J Exp Pathol 86: 365-374, 2005.

5. Petrella BL, Lohi J and Brinckerhoff CE: Identification of membrane type-1 matrix metalloproteinase as a target of hypoxia-inducible factor-2 alpha in von Hippel-Lindau renal cell carcinoma. Oncogene 24: 1043-1052, 2005.

6. Maity A and Solomon D: Both increased stability and transcription contribute to the induction of the urokinase plasminogen activator receptor (uPAR) message by hypoxia. Exp Cell Res 255 : 250-257, 2000

7. Montuori N, Mattiello A, Mancini A, Santoli M, Taglialatela P, Caputi M, Rossi G and Ragno P: Urokinase-type plasminogen activator up-regulates the expression of its cellular receptor through a post-transcriptional mechanism. FEBS Lett 508: 379-384, 2001.

8. Giatromanolaki A, Koukourakis MI, Sivridis E, Turley H, Talks K, Pezzella F, Gatter KC and Harris AL: Relation of hypoxia inducible factor 1 alpha and 2 alpha in operable non-small cell lung cancer to angiogenic/molecular profile of tumours and survival. Br J Cancer 85: 881-890, 2001.

9. Semenza GL: Hypoxia-inducible factors in physiology and medicine. Cell 148: 399-408, 2012.

10. Fukuda R, Zhang H, Kim JW, Shimoda L, Dang CV and Semenza GL: HIF-1 regulates cytochrome oxidase subunits to optimize efficiency of respiration in hypoxic cells. Cell 129: 111-122, 2007.

11. Nishi H, Nakada T, Kyo S, Inoue M, Shay JW and Isaka K: Hypoxia-inducible factor 1 mediates upregulation of telomerase (hTERT). Mol Cell Biol 24: 6076-6083, 2004.

12. McNally SJ, Harrison EM, Ross JA, Garden OJ and Wigmore SJ: Curcumin induces heme oxygenase 1 through generation of reactive oxygen species, p38 activation and phosphatase inhibition. Int J Mol Med 19: 165-172, 2007.
13. Kim J, Yu W, Kovalski K and Ossowski L: Requirement for specific proteases in cancer cell intravasation as revealed by a novel semiquantitative PCR-based assay. Cell 94: 353-362, 1998.

14. Yamano M, Fujii H, Takagaki T, Kadowaki N, Watanabe H and Shirai T: Genetic progression and divergence in pancreatic carcinoma. Am J Pathol 156: 2123-2133, 2000.

15. Lal A, Peters H, St Croix B, Haroon ZA, Dewhirst MW, Strausberg RL, Kaanders JH, van der Kogel AJ and Riggins GJ: Transcriptional response to hypoxia in human tumors. J Natl Cancer Inst 93: 1337-1343, 2001.

16. Koong AC, Denko NC, Hudson KM, Schindler C, Swiersz L, Koch C, Evans S, Ibrahim H, Le QT, Terris DJ, et al: Candidate genes for the hypoxic tumor phenotype. Cancer Res 60: 883-887, 2000.

17. Graham CH, Forsdike J, Fitzgerald CJ and MacdonaldGoodfellow S: Hypoxia-mediated stimulation of carcinoma cell invasiveness via upregulation of urokinase receptor expression. Int J Cancer 80: 617-623, 1999.

18. Mazar AP, Henkin J and Goldfarb RH: The urokinase plasminogen activator system in cancer: Implications for tumor angiogenesis and metastasis. Angiogenesis 3: 15-32, 1999.

19. Bauer TW, Liu W, Fan F, Camp ER, Yang A, Somcio RJ, Bucana CD, Callahan J, Parry GC, Evans DB, et al: Targeting of urokinase plasminogen activator receptor in human pancreatic carcinoma cells inhibits c-Met- and insulin-like growth factor-I receptor-mediated migration and invasion and orthotopic tumor growth in mice. Cancer Res 65: 7775-7781, 2005.

20. Reuning U, Sperl S, Kopitz C, Kessler H, Krüger A, Schmitt M and Magdolen V: Urokinase-type plasminogen activator (uPA) and its receptor (uPAR): Development of antagonists of uPA/uPAR interaction and their effects in vitro and in vivo. Curr Pharm Des 9: 1529-1543, 2003.

21. Degryse B, Sier CF, Resnati M, Conese M and Blasi F: PAI-1 inhibits urokinase-induced chemotaxis by internalizing the urokinase receptor. FEBS Lett 505: 249-254, 2001.

22. Ramont L, Pasco S, Hornebeck W, Maquart FX and Monboisse JC: Transforming growth factor-betal inhibits tumor growth in a mouse melanoma model by down-regulating the plasminogen activation system. Exp Cell Res 291: 1-10, 2003.

23. Fox SB, Taylor M, Grøndahl-Hansen J, Kakolyris S, Gatter KC and Harris AL: Plasminogen activator inhibitor-1 as a measure of vascular remodelling in breast cancer. J Pathol 195: 236-243, 2001.

24. Büchler P, Reber HA, Tomlinson JS, Hankinson O, Kallifatidis G, Friess H, Herr I and Hines OJ: Transcriptional regulation of urokinase-type plasminogen activator receptor by hypoxiainducible factor 1 is crucial for invasion of pancreatic and liver cancer. Neoplasia 11: 196-206, 2009.

25. Montagne M, Naud JF, McDuff FO and Lavigne P: Toward the elucidation of the structural determinants responsible for the molecular recognition between Mad1 and Max. Biochemistry 44: 12860-12869, 2005.

26. Hu J, Banerjee A and Goss DJ: Assembly of b/HLH/z proteins c-Myc, Max, and Mad1 with cognate DNA: Importance of protein-protein and protein-DNA interactions. Biochemistry 44: 11855-11863, 2005.

27. Semov A, Marcotte R, Semova N, Ye X and Wang E: Microarray analysis of E-box binding-related gene expression in young and replicatively senescent human fibroblasts. Anal Biochem 302: 38-51, 2002.

28. Vervoorts J and Lüscher B: DNA binding of Myc/Max/Mad network complexes to oligonucleotides containing two $\mathrm{E}$ box elements: c-Myc/Max heterodimers do not bind DNA cooperatively. Biol Chem 380: 1121-1126, 1999.

29. Koshiji M, Kageyama Y, Pete EA, Horikawa I, Barrett JC and Huang LE: HIF-lalpha induces cell cycle arrest by functionally counteracting Myc. EMBO J 23: 1949-1956, 2004.

30. Powis G and Kirkpatrick L: Hypoxia inducible factor-1alpha as a cancer drug target. Mol Cancer Ther 3: 647-654, 2004. 